\title{
Production Site of Red Sea Bream Pagrus major Intraperitoneal Free Cells: Morphological Study
}

\author{
Tasuku Watanabe, ${ }^{* 1}$ Naoya Kubo, ${ }^{* 2}$ Hiroshi Ohta, ${ }^{* 2}$ \\ Michiko Kono, ${ }^{* 3}$ and Kiyoshi Furukawa*4 \\ ${ }^{*}$ Laboratory of Fish Pathology, School of Fisheries Sciences, Kitasato University, \\ Sanriku, Iwate 022-0101, Japan \\ ${ }^{*}$ Laboratory of Fish Pathology, Department of Veterinary Sciences, Nihon University, \\ Fujisawa, Kanagawa 252-0813, Japan \\ ${ }^{*}$ Fisheries Research Laboratory, University of Tokyo, Maisaka, Shizuoka 431-0211, Japan \\ ${ }^{*}$ Department of Aquatic Bioscience, Graduate School of Agricultural and Life Sciences, \\ University of Tokyo, Bunkyo, Tokyo 113-0032, Japan
}

(Received September 2, 1997)

\begin{abstract}
We examined the production site of the resident intraperitoneal free cells of red sea bream Pagrus major, histologically and electron microscopically. There were many large round cells in mesenteriolum and the adjacent coelomic space near head kidney. Electron microscopical observation showed that the large round cells observed in the mesenteriolum and the adjacent coelomic space were a few heterophilic granulocytes and abundant large cells with similar morphologies of those observed in the abdominal cavity. In the mesenteriolum and the adjacent coelomic space, there were a few fibroblastic cells with many oval granular or vacuole-like structures, which had morphological similarity to the granules of peritoneal large cells. There were abundant round cells in mesenteries, most of which were heterophilic granulocytes. The 5-bromo-2'-deoxyuridine incorporation experiment revealed that these cells observed in the interstitial tissue were not aged but the young cells within 4 days after cell division. The results obtained in this study suggest that mesenteriolum and the adjacent coelomic space near head kidney are one of the pathways of granulocytes and large cells to abdominal cavity and provides the field of large cell production.
\end{abstract}

Key words: macrophage, heterophilic granulocyte, fish, mesentery, mesenteriolum, BrdU incorporation

Marine teleosts have several kinds of intraperitoneal free cells, differing from freshwater fish and mammals. ${ }^{1)}$ One of them, the red sea bream Pagrus major, which is one of the most important fish in Japanese fisheries, has three kinds of resident peritoneal cells: resident peritoneal macrophages, heterophilic granulocytes, and unclassified large round cells (large cells). In the previous paper, ${ }^{2)}$ we described the morphology and distribution of the resident peritoneal cells of red sea bream. The resident peritoneal macrophages of the species proliferate not only in the abdominal cavity but also in vitro. ${ }^{3)}$ However, the production site of the other kinds of cells, heterophilic granulocytes and large cells, remains unknown. We therefore examined the parietal and visceral peritoneum of red sea bream, histologically and electron microscopically. We found that the mesenteriolum and the adjacent coelomic space near head kidney and mesenteries might be the production sites and the pathways to the abdominal cavity of heterophilic granulocytes and large cells.

\section{Materials and Methods}

\section{Fish}

Three-month-old red sea bream $(5.0-8.0 \mathrm{~g}$ body weight and $5.0-6.0 \mathrm{~cm}$ body length) were used for the histological studies, and 5-bromo-2'-deoxyuridine (BrdU) incorporation. One-year-old fish (334-460 $\mathrm{g}$ body weight and 19.0$24.6 \mathrm{~cm}$ body length) were used for the electron microscopical examination. The fish were cultured at the Fisheries Research Laboratory, University of Tokyo, by feeding with a mixture of commercial eel diet (Chubu Shiryo Co., Ltd., Aichi) and minced krill.

\section{Light Microscopy}

The media and procedures for procuring peritoneal cells (RPMI-1640 medium for red sea bream: SB-RPMI) were described previously. ${ }^{2)}$ For histological studies, head kidneys and surrounding tissues were fixed with $10 \%$ formalin in $0.15 \mathrm{M}$ phosphate buffer ( $\mathrm{pH} 7.4$ ) for one week. The tissues containing bones were decalcified with $5 \%$ ethylene diamine tetraacetic acid (EDTA) for one week at room temperature after fixation. After being embedded in paraffin, sections were stained with hematoxylin and eosin.

\section{Electron Microscopy}

The head kidney and surrounding tissues of red sea bream were fixed with $2.5 \%$ glutaraldehyde in $0.15 \mathrm{M}$ cacodyrate buffer (pH 7.4: SB-CB) at $4^{\circ} \mathrm{C}$ for $2 \mathrm{~h}$. The procedures of postfixation, embedding, and stain were described previously. ${ }^{2)}$ 


\section{Incorporation of $\mathrm{BrdU}$}

Proliferating cells were detected by using a Cell Proliferation Kit (Amersham, UK) of BrdU. ${ }^{4-6)}$ Fish were administered once with $60 \mu \mathrm{g} / \mathrm{g} \mathrm{B.W}$. of BrdU orally in diet. The tissues of each of five fish were fixed with $10 \%$ formalin described above $2,4,6$, and 8 days after administration. The sections were reacted with anti-BrdU monoclonal antibody and deoxyribonuclease for one hour according to the manufacturer's instructions. After being washed with phosphate buffered saline (PBS), the sections were stained with anti-mouse $\mathrm{IgG}_{2}$ goat $\mathrm{IgG}$ labeled with horseradish peroxidase, followed by reaction with $0.5 \mathrm{~g} / l$ of diaminobentidine and $170 \mu \mathrm{g} / l$ of $\mathrm{H}_{2} \mathrm{O}_{2}$ in PBS.

\section{Results}

\section{Mesenteriolum and the Adjacent Coelomic Space Near Head Kidney}

Light microscopically, the mesenteriolum and the adjacent coelomic space near head kidney of red sea bream consisted of connective tissues and free round cells (Fig. 1). The abdominal cavity surrounded by pericardial membrane, air bladder, esophagus, stomach, and liver was occupied by intraperitoneal free cells. The round cells in the mesenteriolum and the adjacent coelomic space near head kidney had the similar morphology of peritoneal large cells with marginal, condensed nucleus and round shape and heterophilic granulocytes with eosinophilic cytoplasm (Fig. 2). Electron microscopically, there were also abundant large round cells with a marginal nucleus in the mesenteriolum and the adjacent coelomic space near head kidney (Fig. 3, arrows). These cells were similar to resident peritoneal large cells, morphologically. There were a few comparatively smaller cells than large cells with abundant intracytoplasmic granules (Fig. 3, arrow heads). These granules were similar in morphology to those of heterophilic granulocytes observed in head kidney, blood stream, and abdominal cavity. Occasionally, we could detect small fibroblastic or undifferentiated mesenchymal cells with a large nucleus and round granular or vacuolous structures similar to the granules of peritoneal large cells, in the mesenteriolum and the adjacent coelomic space near head kidney (Fig. 4).

\section{Mesenteries}

There were abundant round cells in the connective tissues of mesenteries, histologically. They had eosinophilic cytoplasm, when stained with hematoxylin and eosin (Fig. 5). Electron microscopically, the mesenteries were occupied with heterophilic granulocytes, which had abundant granules similar to those of the granulocytes observed in head kidney and abdominal cavity (Fig. 6).

\section{Incorporation of $\mathrm{BrdU}$}

After the oral administration of BrdU, the incorporated chemicals were scarcely detected in the tissues of day- 2 samples, except head kidney. In day-4 samples, some of peritoneal cells and interstitial free cells incorporated BrdU (Fig. 7), whereas most of the cells in interstitial tissue, abdominal cavity, and mesenteries incorporated $\mathrm{BrdU}$ in fish 6 days and 8 days after administration. Especially, the marginal small nuclei of large round cells were stained strongly with the anti-BrdU antibody (Fig. 7, 8, arrows). Some of the intraperitoneal free cells near the pericardial membrane were also stained by the antibody. Only a few cells in mesenteries incorporated BrdU in day- 4 samples.

\section{Discussion}

Histological examination of red sea bream reveals that many intraperitoneal free cells are present in the anterior abdominal cavity surrounded by pericardial membrane, air bladder, esophagus, stomach, and liver and that this space is most abundant in resident peritoneal cells. The space prior to the liver of the abdominal cavity is the most suitable for obtaining red sea bream intraperitoneal free cells. ${ }^{2)}$ Therefore, we expected that there were routes other than the blood stream by which intraperitoneal free cells moved from hematopoietic tissue to the abdominal cavity. Detailed structural examination also indicates that there are many heterophopic granulocytes in mesenteries. The human mesenteries are known to consist of loose connective tissue with fibroblasts, mast cells, and macrophages (histiocytes). ${ }^{7,87}$ We could not detect other cellular components than heterophilic granulocytes and a few large cells in red sea bream mesenteries. The data suggests that the resident peritoneal granulocytes may migrate from hematopoietic tissues to the abdomen through mesenteries and that the mesenteries of this species of marine fish have unique appearances differing from mammalian mesenteries.

There are abundant large cells and a few heterophilic granulocytes in the mesenteriolum and the adjacent coelomic space near head kidney. We also detected fibroblastic or undifferentiated mesenchymal cells with many granular or vacuolar structures which had similar morphological characteristics to the granules of the peritoneal large cells. The BrdU incorporation experiment indicates that they are young cells soon after cell division (within 4 days) as both cells incorporated $\mathrm{BrdU}$ into nuclei, clearly showing that the morphological characteristics of the large cells are not the result of cell aging. The result also suggests that the red sea bream heterophilic granulocytes have a longer life span than mammalian neutrophils. ${ }^{9)}$ The data also suggests that the source of large cells may be mesenteriolum and the adjacent coelomic space near head kidney, especially neighboring head kidney, as we could not detect large cells in the blood stream or head kidney hematopoietic tissue.) Mouse fibroblasts become heavily granulated or vacuolated, the morphology of which resembles those of red sea bream peritoneal large cells, when cocultured with bone marrow mast cells. ${ }^{10)} \mathrm{F}$. Levi-Schaffer et al. suggested that the morphological changes of cocultured fibroblasts were due to the effects of histamine and prostaglandins released by mast cells. ${ }^{10,11)}$ Therefore, we could not deny the possibility that the origin of red sea bream peritoneal large cells was vacuolar degenerated or edematous interstitial fibroblasts. However, all fish used (more than $100 \mathrm{fish}$ ) had healthy appearances, though these degenerative changes are induced by the pathological effects of mast cells in inflammation. In fish tissues, there is no evidence for the presence of a mast cell or basophilic granulocyte with functional characteristics analogous to those of mammalian 

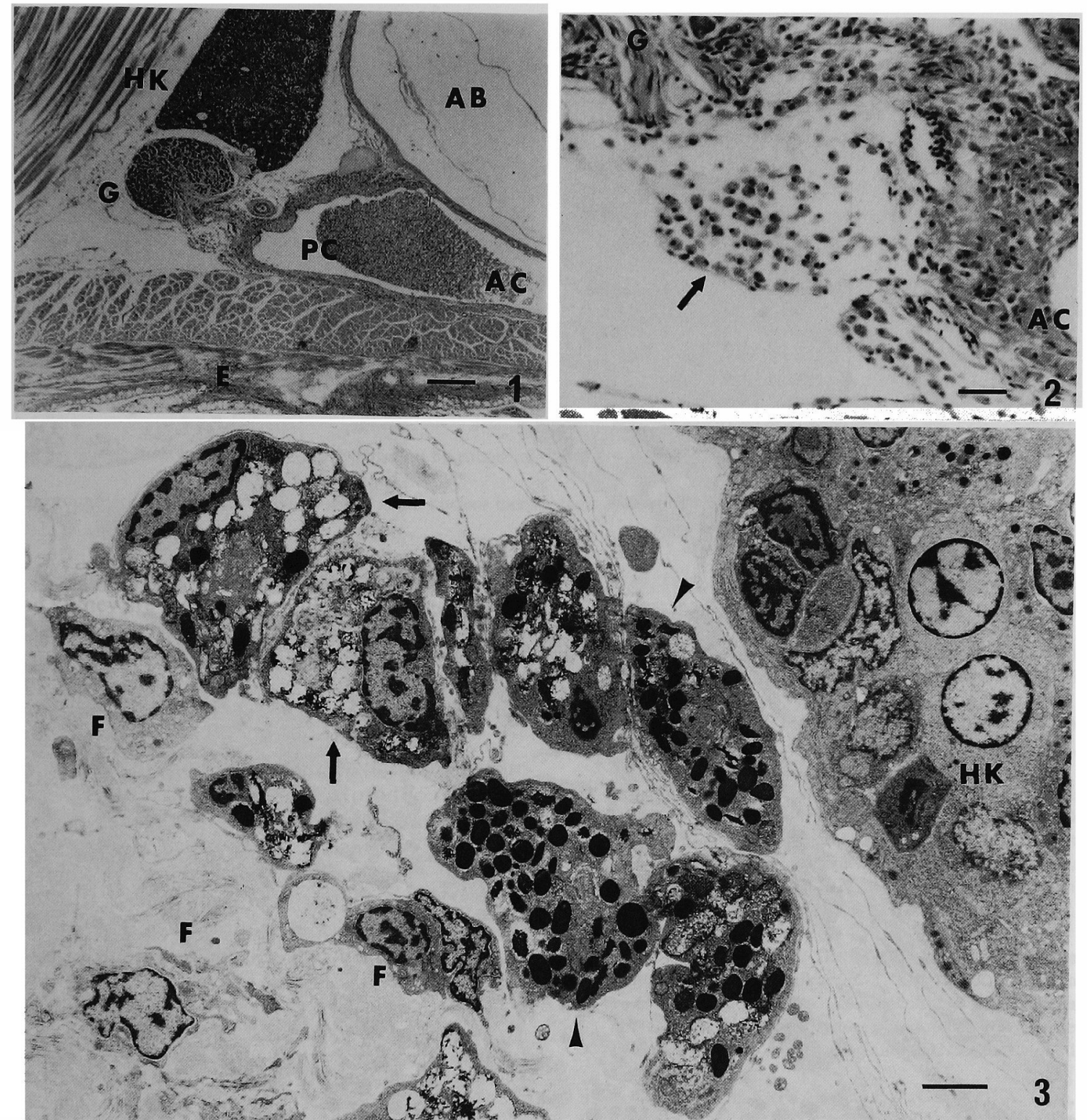

Fig. 1. Sagittal sectio of mesenteriolum and the adjacent coelomic space near head kidney (HK) of red sea bream.

Note abundant free cells (PC) in the abdominal cavity (AC). AB: air bladder; E: esophagus; G: ganglion. Hematoxylin-eosin stain. Bar=100 $\mu \mathrm{m}$.

Fig. 2. High magnification of the the mesenteriolum and the adjacent coelomic space near head kidney, showing many large round cells with a marginal condensed nucleus (arrow).

AC: abdominal cavity; G: ganglion. Hematoxylin-eosin stain. Bar $=10 \mu \mathrm{m}$.

Fig. 3. Electron photomicrograph of the mesenteriolum and the adjacent coelomic space neighboring head kidney (HK).

Note the large round cells with a marginal nucleus and electron-lucent granular or vacuolar structures (arrows) and the cells with electron-dense granules (arrow heads). F: fibroblast or undifferentiated mesenchymal cells. Bar $=2 \mu \mathrm{m}$.

mast cells. The functions and roles of peritoneal large cells remain for further investigations.

Resident and exudate macrophages of mammals have been used in many immunological experiments. ${ }^{12)}$ However, other cells such as neutrophils are less common components of peritoneal cells and seldom used. In mammals, most of exudate peritoneal macrophages are thought to migrate from the blood stream. ${ }^{13)}$ We suggested previously that chemotactic factor-like substances released by resident peritoneal macrophages induced the migration of other intraperitoneal free cells. ${ }^{3,14)}$ The data obtained in this work suggest that other routes and mechanisms than those of mammals may be present in intraperitoneal free cells. There have been few researches on the origin and production site of fish intraperitoneal free cells. We observed the cells in the mesenteriolum and the adjacent coelomic space near head kidney. As the cells incorporated BrdU, the cells are not "old" cells but newly proliferated young cells. Although we did not examine every tissue of red sea bream, histological observation showed that the tis- 


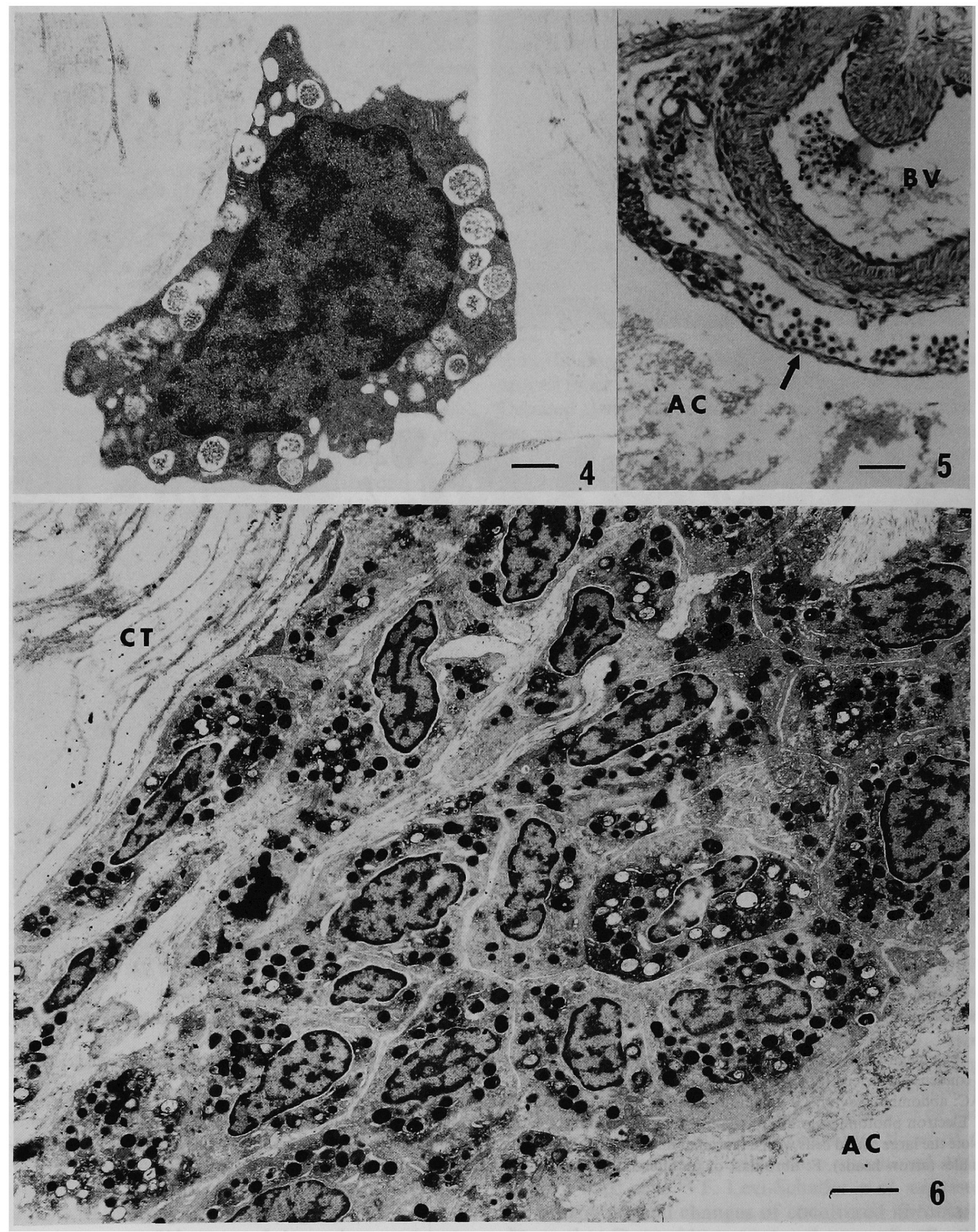

Fig. 4. Electron photomicrograph of a fibroblast or undifferentiated mesnchymal cells with a centrally located large nucleus and abundant electronlucent granular or vacuolar structures. Bar $=500 \mathrm{~nm}$.

Fig. 5. The mesentery of red sea bream, showing abundant round cells in connective tissues (arrow). AC: abdominal cavity; BV: blood vessel. Hematoxylin-eosin stain. Bar $=5 \mu \mathrm{m}$.

Fig. 6. Electron photomicrograph of a mesentery of red sea bream, showing abundant heterophilic granulocytes in connective tissues (CT) nearby abdominal cavity (AC).

$\mathrm{Bar}=2 \mu \mathrm{m}$. 

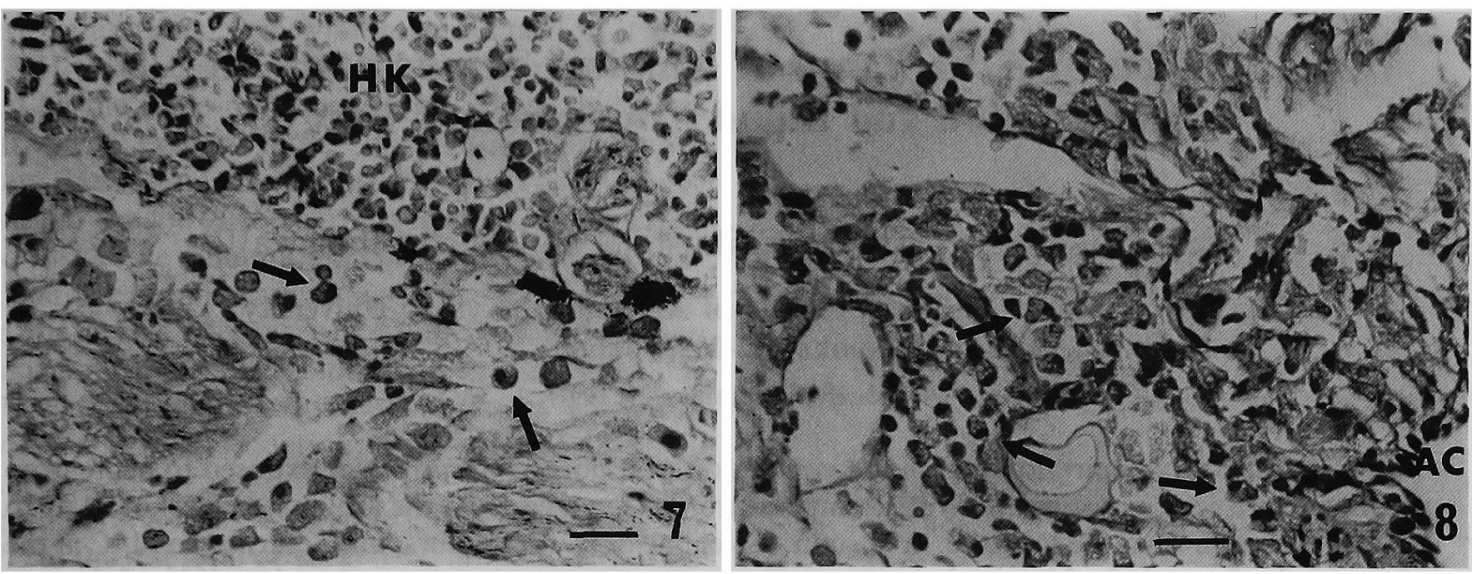

Figs. 7 and 8. Bromodeoxyuridine (BrdU) incorporation by round cells in the interstitial tissues between head kidney (HK) and abdominal cavity (AC).

Large round cells with a peripherally located small nucleus incorporated BrdU (arrows: darkly stained nuclei). Bar $=10 \mu \mathrm{m}$.

sues of mesenteriolum and the adjacent coelomic space near head kidney are the most rich place in "large cells" in internal organs and tissues neighboring the abdomen. The BrdU incorporation experiment and electron microscopical observation suggest that the connective tissue of mesenteriolum and the adjacent coelomic space near head kidney is the one of the "large-cell-poietic" places.

Mesenteries are the most heterophilic granulocyte-abundant place. Heterophilic granulocytes produced in head kidney and body kidney hematopoietic tissues may migrate to mesenteries by the blood stream and the mesenteriolum and the adjacent coelomic space near head kidney. However, it is also important to study the origin of heterophilic granulocytes and large cells in mesenteriolum and the adjacent coelomic space near head kidney.

Acknowledgments We are grateful to the staff and students of Fisheries Research Laboratory, University of Tokyo, for culturing and maintaining the cultured fish used in this study. This work was supported in part by a Grant-in-Aid for Scientific Research from the Ministry of Education, Science and Culture.

\section{References}

1) T. Watanabe, K. Kitayama, T. Takagi, J. Murata, M. Kono, T. Takase, and K. Furukawa: Heterogeneity of peritoneal cells in marine teleosts. Fisheries Sci., 63, 576-581 (1997).

2) T. Watanabe, A. Kamijo, H. Narita, K. Kitayama, H. Ohta, N. Kubo, T. Moritomo, M. Kono, and K. Furukawa: Resident peritoneal cells of red sea bream Pagrus major. Fisheries Sci., 61, 937-941 (1995)

3) T. Watanabe, T. Shoho, H. Ohta, N. Kubo, M. Kono, and K. Furukawa: Long-term cell culture of resident peritoneal macrophages from red sea bream Pagrus major. Fisheries Sci., in press.

4) H. G. Gratzner: Monoclonal antibody to 5-bromo- and 5-iododeoxyuridine: A new reagent for detection of DNA replication. Science, 218, 474-475 (1982).
5) J. W. Truman and M. Bate: Spatial and temporal patterns of neurogenesis in the central nervous system of Drossophila melanogaster. Dev. Biol., 125, 145-157 (1988).

6) K. Ito and Y. Hotta: Proliferation pattern of postembryonic neuroblasts in the brain of Drosophila melanogaster. Dev. Biol., 149 134-148 (1992).

7) U. Welsch and V. Storch: Comparative Animal Cytology and Histology, Sidgwick and Jackson Limited, London, UK, 1976, p. 343.

8) L. C. Junqueira, J. Carneiro, and R. O. Kelley: Basic Histology, 8th ed., Prentice-Hall Int. Inc., London, UK, 1995, p. 488.

9) D. F. Bainton: Developmental biology of neutrophils and eosinophils. In "Inflammation: Basic Principles and Clinical Correlates, 2nd ed." (ed. by J. I. Gallin, I. M. Goldstein, and R. Snyderman), Raven Press, Ltd., New York, USA, 1992, pp. 303324.

10) F. Levi-Schaffer, E. T. Dayton, K. F. Austen, A. Hein, J. P. Caulfield, P. M. Gravallese, F.-T. Liu, and R. L. Stevens: Mouse bone marrow-derived mast cells cocultured with fibroblasts. Morphology and stimulation-induced release of histamine, leukotriene B4, leukotriene C4, and prostaglandin D2. J. Immunol., 139, 34313441 (1987).

11) F. Levi-Schaffer, K. F. Austen, J. P. Caulfield, A. Hein, J. P. M. Gravallese, and R. L. Stevens: Co-culture of human lung-derived mast cells with mouse 3T3 fibroblasts: Morphology and IgE-mediated release of histamine, prostaglandin D2, and leukotrienes. $J$. Immunol., 139, 494-500 (1987).

12) J. M. Papadimitriou and R. B. Ashman: Macrophageds: current views on their differentiation, structure, and function. Ultrastr. Pathol., 13, 343-372 (1989).

13) R. van Furth: Development and distribution of mononuclear phagocytes, in "Inflammation: Basic Principles and Clinical Correlates, Second Edition"' (ed by J. I. Gallin, I. M. Goldstein, and R. Snyderman), Raven Press, Ltd., New York, USA, 1992, pp. 325-339.

14) T. Watanabe: The properties and defense mechanisms of fish phagocyte system. In "Animal Blood Cells and Host Defense" (ed. by H. Wago), Saikon Shuppan, Tokyo, Japan, 1997, pp. 157-178 (in Japanese). 